Оруджев Ф.Ф., Исаев А.Б., Гасанова Ф.Г., Шабанов Н.С. Кинетика фотокаталитического окисления фенола на $\mathrm{CuO}-\mathrm{TiO}_{2}$ под давлением кислорода

УДК 544.478.12

Химия

DOI: $10.21779 / 2542-0321-2016-31-3-68-75$

Ф.Ф. Оруджев, А.Б. Исаев, Ф.Г. Гасанова, Н.С. Шабанов

Кинетика фотокаталитического окисления фенола на СuO-TiO 2 под давлением кислорода

Дагестанский государственный университет; Россия, 367001, г. Махачкала, ул. М. Гаджиева, 43a; farid-stkha@mail.ru; abdul-77@yandex.ru

Изучено фотокаталитическое окисление фенола на композиционном полупроводниковом фотокатализаторе из диоксида титана, модифицированного оксидом меди (II), при облучении дневным светом. Показано, что проведение процесса окисления в присутствии кислорода повышает эффективность процесса примерно в 1,2 раза.

Ключевые слова: фенол, композиционный фотокатализатор, диоксид титана, кислород, квантовый выход, кинетика.

\title{
Введение
}

Токсичность фенола даже при низких его концентрациях в промышленных стоках достаточно высока. Исходя из этого, в настоящее время для удаления фенола из сточных вод используют различные физико-химические методы. Для удаления фенола при высоких концентрациях рекомендуется использовать экстракцию, адсорбцию, мембранные технологии. При низких концентрациях используется биологическое, электрохимическое, химическое, фотохимическое, фотокаталитическое окисление, озонирование, жидкофазное окисление при высоких давлениях и температурах [1-4].

Среди окислительных методов удаления фенола из природных и сточных вод при низких концентрациях интерес представляют фотокаталитические методы. Впервые фотокаталитический метод для удаления различных органических соединений был использован в работе А. Фуджишима в 1970 году [5]. Позже было разработано большое количество разнообразных фотокатализаторов, использующих солнечную энергию при окислении различных органических соединений. Однако диоксид титана $\left(\mathrm{TiO}_{2}\right)$ попрежнему является одним из наиболее используемых в фотокатализе материалов из-за его дешевизны, нетоксичности, устойчивости к облучению и легкого синтеза [6-8]. Большое значение ширины запрещенной зоны диоксида титана $(3,2$ эВ) и быстрая рекомбинация фотогенерированных электронов и дырок ограничивают широкое применение и распространение материалов на основе диоксида титана в фотокатализе. Для смещения спектра поглощения диоксида титана в область дневного света производят легирование его поверхности ионами переходных металлов, допирование благородными металлами и неметаллами, функционализацию поверхности акцепторами и создают композиты с полупроводниками с малой шириной запрещенной зоны [9]. Кроме того, допирование в структуру $\mathrm{TiO}_{2}$ различных элементов приводит к повышению его фотокаталитической активности [10-13].

Работы $[14,15]$ содержат сведения об использовании наночастиц $\mathrm{Pt} / \mathrm{TiO}_{2}$ в качестве фотокатализатора при окислении фенола и 2-хлорфенола в модельных растворах. Кроме того, существуют исследования по допированию диоксида титана другими ме- 
Оруджев Ф.Ф., Исаев А.Б., Гасанова Ф.Г., Шабанов Н.С. Кинетика фотокаталитического окисления фенола на $\mathrm{CuO}-\mathrm{TiO}_{2}$ под давлением кислорода

таллами, такими, как железо, празеодим, кобальт, и их использованию для окисления фенола при облучении дневным светом [16-19].

Добавление к диоксиду титана оксидов других элементов приводит к увеличению фотокаталитической активности при облучении УФ-светом $[20,21]$. Использование оксидов меди в качестве добавок к диоксиду титана также приводит к повышению активности фотокатализатора при облучении дневным светом. В частности, в работе [22] приводятся сведения по фотокаталитическому окислению $n$-нитрофенола на $\mathrm{Cu}_{2} \mathrm{O} / \mathrm{TiO}_{2}$. В другой работе [23] сообщается об увеличении фотокаталитической активности диоксида титана при добавлении оксида меди (II) с концентрацией $0,1 \%$ от общей массы катализатора. Добавление оксидов металлов к диоксиду титана приводит к уменьшению скорости рекомбинации пары электрон-дырка, а также увеличивает площадь поверхности и способствует активации при облучении дневным светом [24].

В данной работе исследовано фотокаталитическое окисление фенола на композиционном нанодисперсном полупроводниковом фотокатализаторе из диоксида титана, модифицированного оксидом меди (II), при облучении дневным светом.

\section{Методика эксперимента}

Фотокатализатор $\mathrm{CuO}-\mathrm{TiO}_{2}$ был получен методом комплексного осаждения. В качестве базового материала использовали $\mathrm{TiO}_{2}$, содержащий преимущественно фазу анатаза. Нитрат меди трехводный, $\mathrm{Cu}\left(\mathrm{NO}_{3}\right)_{2} \cdot 3 \mathrm{H}_{2} \mathrm{O}$ (98 \% чистоты), был использован в качестве легирующей примеси. Глицерин (95 \% чистоты) использовали в качестве комплексообразующего агента на медь. Гидроксид натрия, $\mathrm{NaOH}$ (95 \% чистоты), был использован в качестве осаждающего агента.

В водный раствор $\mathrm{Cu}\left(\mathrm{NO}_{3}\right)_{2} \cdot 3 \mathrm{H}_{2} \mathrm{O}$ добавляют глицерин (при мольном соотношении $\mathrm{Cu}$ : глицерин $=1: 2$ ) для получения медно-глицеринового комплекса. Затем в этот раствор при непрерывном перемешивании добавляют порошок $\mathrm{TiO}_{2}$ до образования суспензии. Медно-глицериновый комплекс осаждают на частицы $\mathrm{TiO}_{2}$ путем добавления к суспензии по каплям при постоянном перемешивании $0,25 \mathrm{M} \mathrm{NaOH}$. Образовавшийся осадок интенсивно перемешивают в течение 30 мин с последующей фильтрацией и сушкой в течение 5 часов при $70{ }^{\circ} \mathrm{C}$. Затем образцы прокаливают в муфельной печи при $500{ }^{\circ} \mathrm{C}$ в течение 30 мин.

Для характеристики полученного фотокатализатора были использованы методы электронной микроскопии, рентгенофазового анализа. Изображение поверхности синтезированного образца получили с использованием электронного растрового сканирующего микроскопа Aspex express vp (Fei corp, CША). Рентгенофазовый анализ осуществлялся на дифрактометре Empyrean series 2 фирмы PANalytical.

Фотокаталитическое окисление фенола проводили в ячейке, более подробно описанной нами ранее в работах $[25,26]$. В качестве источника видимого света использовали лампу Paulmann Energy-saving lamp, spiral, 20W E14, warm white с преимущественной длиной волны 610 нм. В ячейку для фотокатализа помещали модельный раствор, содержащий фенол, в объем раствора добавляли фотокатализатор, концентрация которого составляла 0,1 г/л. Эксперимент проводили в течение одного часа, пробы брали через каждые 15 минут, подвергали центрифугированию для отделения осадка и определяли концентрацию фенола флуориметрическим методом. Начальная концентрация фенола составляла 10 мг/л.

\section{Результаты и их обсуждение}

На рис. 1 приведены изображение поверхности и рентгенограмма образца Сu$\mathrm{TiO}_{2}$. Как видно из рис. 1 (а), образец имеет пористую структуру с различными разме- 
Оруджев Ф.Ф., Исаев А.Б., Гасанова Ф.Г., Шабанов Н.С. Кинетика фотокаталитического окисления фенола на $\mathrm{CuO}-\mathrm{TiO}_{2}$ под давлением кислорода

рами частиц. Рентгенограмма образца катализатора, приведенная на рис. 1 (б), показывает, что фотокатализатор имеет смешанную кристаллическую структуру, содержит оксид титана в фазе анатаза и оксид меди (II). Как показывают результаты рентгеноструктурного анализа, содержание оксида меди (II) в композиционном фотокатализаторе составляет примерно $3 \%$.
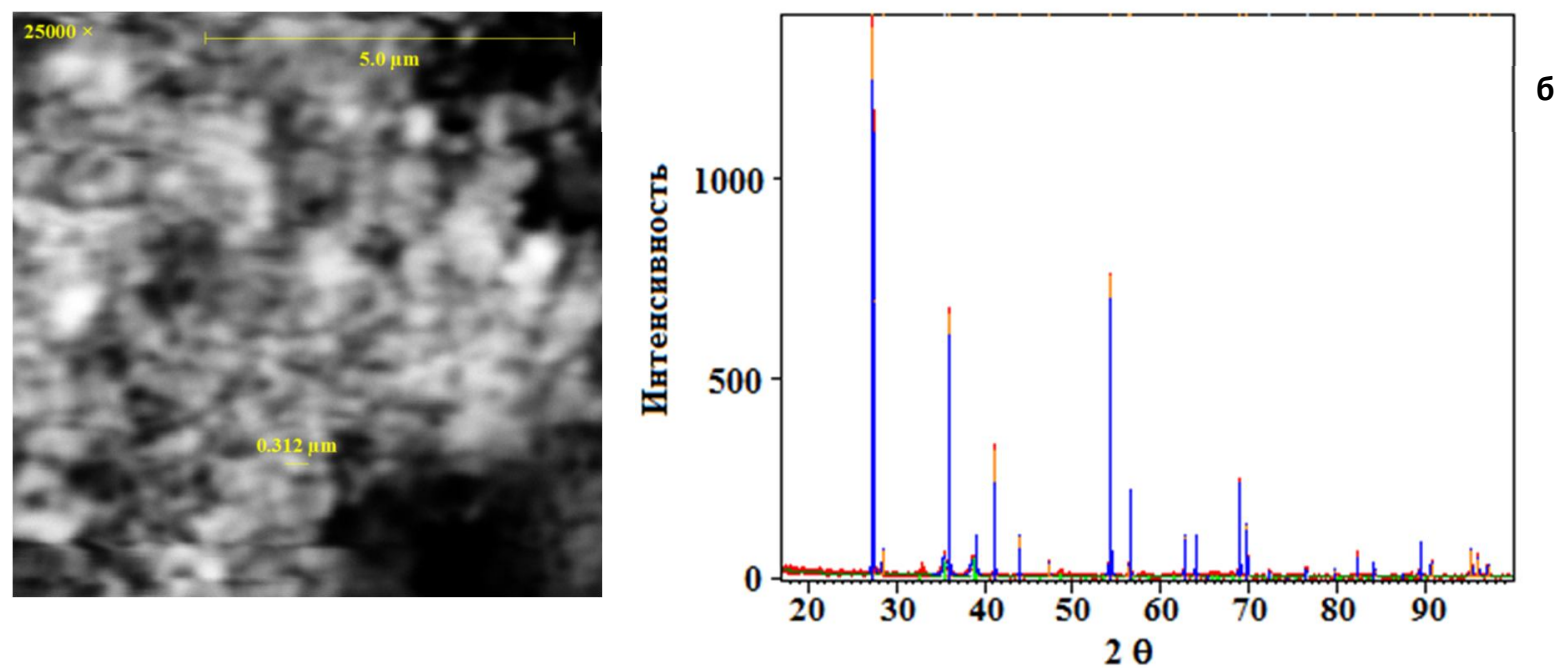

Рис. 1. Изображение поверхности образца (а) и рентгенограмма (о) композиционного фотокатализатора $\mathrm{CuO}-\mathrm{TiO}_{2}$

Фотокаталитический процесс на $\mathrm{CuO}-\mathrm{TiO}_{2}$ при облучении дневным светом протекает за счет активации оксида меди (II). Чистый $\mathrm{TiO}_{2}$ поглощает свет в основном в УФобласти, в то время как $\mathrm{CuO}$ поглощает преимущественно в видимой области [27]. Кроме того, наличие оксида меди, действующего в качестве акцептора электрона или дырки, приводит к уменьшению скорости рекомбинации электронно-дырочной пары [28]. На рис. 2 представлены кинетические кривые фотокаталитического окисления фенола на $\mathrm{CuO}-\mathrm{TiO}_{2}$ при различных условиях. Кислород в растворе также выступает в качестве акцептора электрона, что приводит к уменьшению скорости рекомбинации электронов и дырок [29-31]. Процесс проводили, непрерывно подавая в раствор компрессором воздух.

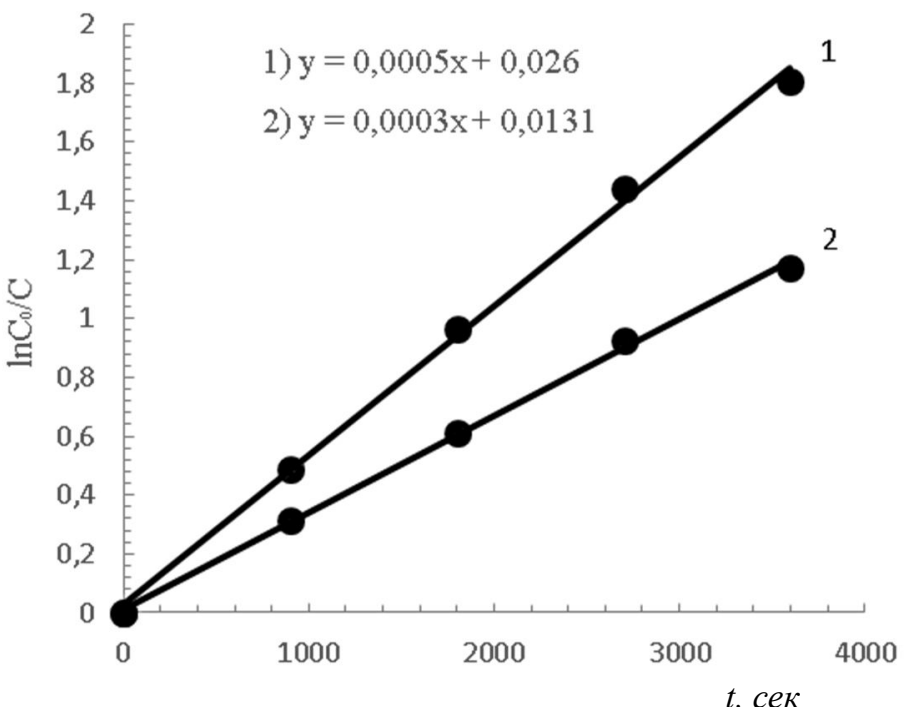


Оруджев Ф.Ф., Исаев А.Б., Гасанова Ф.Г., Шабанов Н.С. Кинетика фотокаталитического окисления фенола на $\mathrm{CuO}-\mathrm{TiO}_{2}$ под давлением кислорода

Рис. 2. Кинетические кривые фотокаталитического окисления фенола при облучении дневным светом: $1-\mathrm{CuO}-\mathrm{TiO}_{2}+\mathrm{O}_{2}, 2-\mathrm{CuO}-\mathrm{TiO}_{2}$

Полученные экспериментальные данные показывают, что использование кислорода делает процесс фотокаталитического окисления фенола более эффективным, повышая степень окисления от 69 до 83,6 \%.

Растворенный кислород при протекании фотокаталитического процесса восстанавливается с образованием супероксидного аниона $\mathrm{O}_{2}^{-}$, который после ряда превращений также преобразуется в гидроксильный радикал ОН [32].

Среди активных продуктов, образующихся при протекании фотокаталитического процесса, наибольшим значением окислительно-восстановительного потенциала, по данным [33], обладают положительно заряженные дырки, локализующиеся на гранях кристаллической решетки $\mathrm{TiO}_{2}-2,35 \mathrm{~B}$, и гидроксильный радикал $-2,80 \mathrm{~B}$ относительно водородного электрода сравнения. Генерированные при облучении на поверхности $\mathrm{CuO}-\mathrm{TiO}_{2}$ дырки и гидроксильные радикалы, по-видимому, взаимодействуют с молекулами фенола с образованием различных ароматических фрагментов и последующей их минерализацией.

Для определения порядка реакции фотокаталитического окисления фенола находили величину константы скорости по уравнению:

$$
k=\frac{1}{t} \ln \frac{100}{100-x},
$$

где $k$ - константа скорости фотокаталитического окисления фенола, $x$ - процентное количество окисленного вещества в данный промежуток времени $t$.

На рис. 3 представлена зависимость константы скорости реакции окисления фенола от времени. Константу скорости окисления фенола определяли по тангенсу угла наклона кинетических кривых. Как видно из рисунка, вариация значений $k$ незначительна, что свидетельствует о первом порядке реакции фотокаталитического окисления фенола.

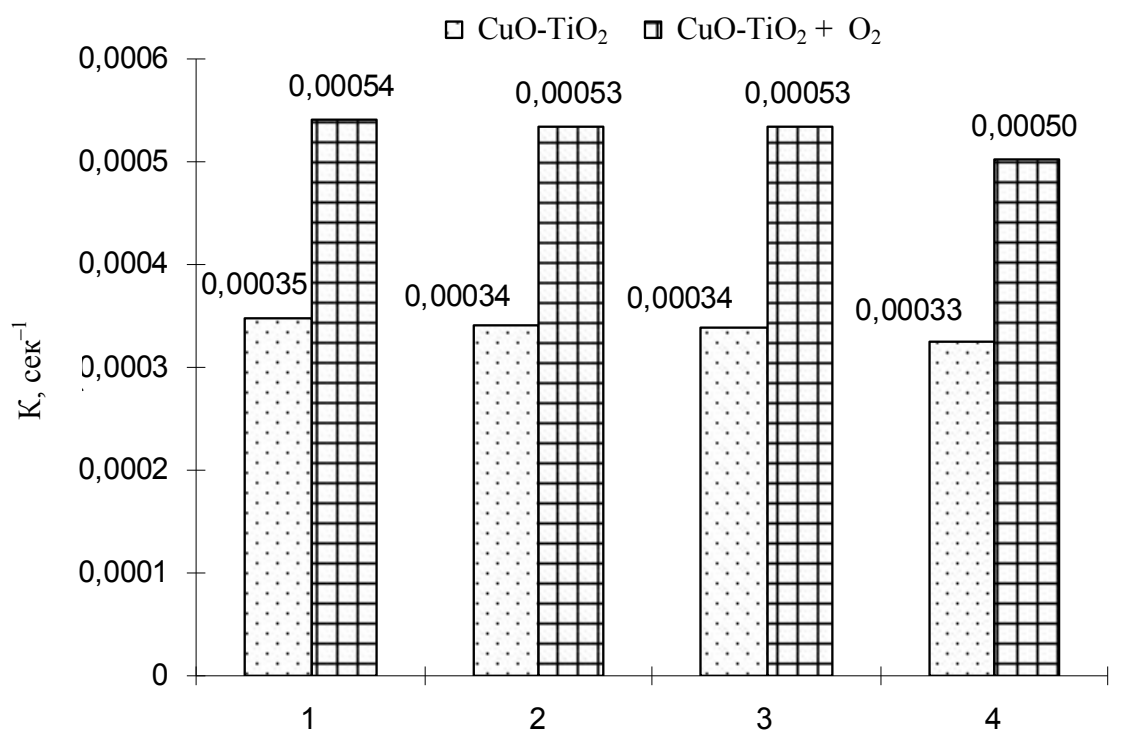

Рис. 3. Зависимость константы скорости реакции окисления фенола от времени: $1-15$, $2-30,3-45,4-60$ мин. 
Оруджев Ф.Ф., Исаев А.Б., Гасанова Ф.Г., Шабанов Н.С. Кинетика фотокаталитического окисления фенола на $\mathrm{CuO}-\mathrm{TiO}_{2}$ под давлением кислорода

Механизм реакции гетерогенного фотокаталитического окисления фенола состоит в его адсорбции на поверхности катализатора с последующим окислением фотогенерированными радикалами. Фотокаталитическое окисление фенола на $\mathrm{CuO}-\mathrm{TiO}_{2}$ подчиняется модели Ленгмюра-Хиншельвуда. Для определения констант уравнения строили зависимость

$$
\frac{1}{r_{0}}=\frac{1}{k_{r}}+\frac{1}{k_{r} \cdot K} \cdot \frac{1}{C_{0}}
$$

где $r_{0}$ - начальная скорость фотокаталитического окисления фенола, $k_{r}$ - константа скорости реакции, $K$ - константа адсорбции фенола на фотокатализаторе, $C_{0}$ - начальная концентрация фенола.

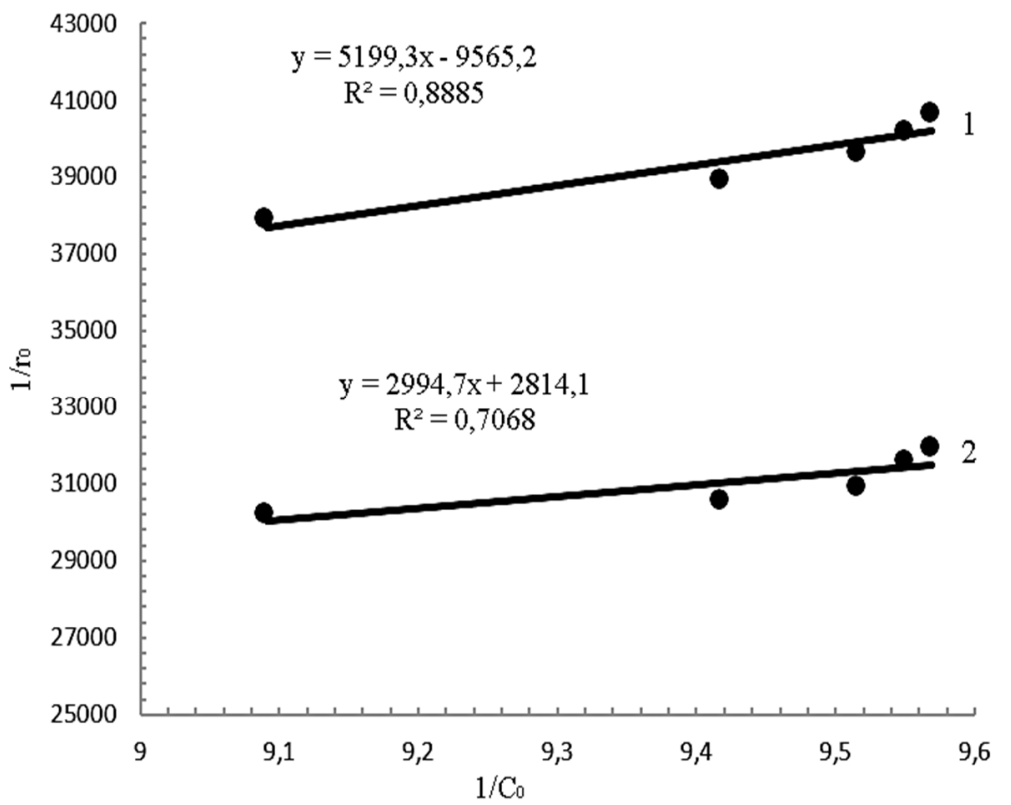

Рис. 4. Зависимость обратной начальной скорости фотокаталитического окисления фенола от обратной начальной концентрации: $1-\mathrm{CuO}-\mathrm{TiO}_{2}, 2-\mathrm{CuO}_{-} \mathrm{TiO}_{2}+\mathrm{O}_{2}$

На рис. 4 показана зависимость обратной начальной скорости фотокаталитического окисления фенола от обратной начальной концентрации.

Значения константы уравнения Ленгмюра-Хиншельвуда для фотокаталитического окисления фенола, характеризующие равновесную адсорбцию на поверхности катализатора и определяющие скорость реакции, приведены в таблице.

Фотоэффективность процесса фотокаталического окисления фенола была оценена с помощью квантового выхода, определяемого как отношение количества прореагировавших молекул к количеству фотонов, поглощенных системой за определенный промежуток времени, в соответствии с уравнением [34].

$$
\Phi_{0}=\frac{r_{0}}{\varphi}
$$

где $\Phi_{0}-$ начальный квантовый выход, $r_{0}$ - начальная скорость фотоокисления, $\varphi-$ поток фотонов.

Рассчитанные значения квантового выхода фотокаталитического окисления фенола также приведены в таблице 1. Как видно из таблицы, при проведении процесса в присутствии кислорода начальная скорость фотокаталитического окисления фенола возрастает примерно в 1,27 раза. 
Оруджев Ф.Ф., Исаев А.Б., Гасанова Ф.Г., Шабанов Н.С. Кинетика фотокаталитического окисления фенола на $\mathrm{CuO}-\mathrm{TiO}_{2}$ под давлением кислорода

Таблица 1

Константы уравнения модели Ленгмюра-Хиншельвуда и начальный квантовый выход фотокаталитического окисления фенола

\begin{tabular}{|c|c|c|c|c|c|}
\hline $\begin{array}{c}\text { Фотокатализа- } \\
\text { тор }\end{array}$ & $\begin{array}{c}\text { Начальная } \\
\text { скорость, } \mathrm{r}_{0}, \\
\text { ммоль } \text { Л }^{-} \cdot \mathrm{ce \kappa}^{-1}\end{array}$ & $\begin{array}{c}\text { Константа } \\
\text { скорости, секк }\end{array}$ & $\begin{array}{c}\text { Константа } \\
\text { адсорбции, } \\
\text { ммоль•л }^{-1}\end{array}$ & $\begin{array}{c}\text { Начальный } \\
\text { квантовый } \\
\text { выход, } \Phi_{0}\end{array}$ & $\mathrm{R}^{2}$ \\
\hline $\mathrm{CuO}-\mathrm{TiO}_{2}$ & $2,46 \cdot 10^{-5}$ & $3,5 \cdot 10^{-4}$ & 0,549 & 0,29 & 0,8885 \\
\hline $\mathrm{CuO}-\mathrm{TiO}_{2}+\mathrm{O}_{2}$ & $3,13 \cdot 10^{-5}$ & $5,4 \cdot 10^{-4}$ & 0,618 & 0,37 & 0,7068 \\
\hline
\end{tabular}

При этом также возрастает величина начального квантового выхода. Повидимому, такой эффект связан с образованием высокоактивных кислородсодержащих окислительных частиц в объеме реактора.

Таким образом, полученные нами экспериментальные данные показывают, что $\mathrm{CuO}-\mathrm{TiO}_{2}$ обладает фотокаталитической активностью при облучении дневным светом. Фотокаталитическое окисление фенола подчиняется модели Ленгмюра-Хиншельвуда. Увеличение активности фотокатализатора в присутствии кислорода связано с образованием активных кислородсодержащих частиц, участвующих в окислении адсорбированных фенола.

\section{Литература}

1. Busca G., Berardinelli S., Resini C., Arrighi L. Technologies for the removal of phenol from fluid streams: a short review of recent developments // Journal of Hazardous Materials. -2008 . - T. 160, № 2. - C. 265-288.

2. Keav S., Monteros A.E., Barbier Jr. J., Duprez D. Wet Air Oxidation of phenol over $\mathrm{Pt}$ and $\mathrm{Ru}$ catalysts supported on cerium-based oxides: Resistance to fouling and kinetic modelling // Applied Catalysis B: Environmental. - 2014. - T. 150. - C. 402-410.

3. Корниенко Г.В., Чаенко Н.В., Максимов Н.Г. и др. Электрохимическое окисление фенола на допированном бором алмазном электроде // Электрохимия. - 2011. T. 47, № 2. - C. 240-245.

4. Гасанова Ф.Г., Оруджев Ф.Ф., Алиев З.М., Исаев А.Б. Влияние давления кислорода на фотохимическое окисление фенола // Ж. физ. химии. -2012 . - Т. 86, № 3 C. 569.

5. Fujishima A. Electrochemical photolysis of water at a semiconductor electrode // Nature. - 1972. - T. 238. - C. 37-38.

6. Воронщов А.В., Козлов Д.В., Смирниотис П.Г., Пармон В.Н. Фотокаталитическое окисление на $\mathrm{TiO}_{2}$. I. Фотокатализаторы для жидкофазных и газофазных процессов и фотокаталитическая деструкция имитантов боевых отравляющих веществ в жидкой фазе // Кинетика и катализ. - 2005. - Т. 46, № 2. - С. 203-218.

7. Федотова М.П., Воронова Г.А., Емельянова Е.Ю. и др. Нанодисперсные фотокатализаторы на основе диоксида титана // Ж. физ. химии. - 2009. - Т. 83, № 8. C. $1539-1543$.

8. Fujishima A., Rao T.N., Tryk D.A. Titanium dioxide photocatalysis // J. Photochem. Photobiol. C: Photochem. Rev. - 2000. - V. 1, № 1. - P. 1-21. 
9. Kumar S.G., Devi L.G. Review on modified $\mathrm{TiO}_{2}$ photocatalysis under UV/visible light: selected results and related mechanisms on interfacial charge carrier transfer dynamics // J. Phys. Chem. A. - 2011. - V. 115, № 46. - P. 13211-13241.

10. Chen X., Mao S.S. Titanium dioxide nanomaterials: synthesis, properties, modifications, and applications // Chem. Rev. - 2007. - V. 107, № 7. - P. 2891-2959.

11. Козлова E.A., Воронщов A.B. Многократное увеличение фотокаталитической активности $\mathrm{TiO}_{2}$ путем сочетания мезопористой структуры и наночастиц платины // Российские нанотехнологии. - 2007. - Т. 2, № 11-12. - С. 72-74.

12. Zhang $D$. Enhancement of the photocatalytic activity of modified $\mathrm{TiO}_{2}$ nanoparticles with $\mathrm{Zn}^{2+}$. correlation between structure and properties // Russ. J. Phys. Chem. A. -2012. - V. 86, № 3. - P. 489-494.

13. Оруджев Ф.Ф., Гасанова Ф.Г., Алиев З.М., Исаев А.Б. Фотоэлектрокаталитическое окисление фенола на модифицированных платиной нанотрубках $\mathrm{TiO}_{2} / /$ Российские нанотехнологии. - 2012. - Т. 7, № 9-10. - С. 44-47.

14. Barakat M.A., Al-Hutailah R.I., Qayyum E. et al. Pt nanoparticles/TiO $\mathrm{T}_{2}$ for photocatalytic degradation of phenols in wastewater // Environ. Technol. - 2014. - V. 35, № 2. P. 137-144.

15. Emilio C.A., Litter M.I., Kunst M. et al. Phenol photodegradation on platinized$\mathrm{TiO}_{2}$ photocatalysts related to charge-carrier dynamics // Langmuir. - 2006. - V. 22, № 8. P. 3606-3613.

16. Shawabkeh R.A., Khashman O.A., Bisharat G.I. Photocatalytic Degradation of Phenol using $\mathrm{Fe}_{-} \mathrm{TiO}_{2}$ by Different Illumination Sources // Int. J. Chem. - 2010. - V. 2, № 2 P. 10 .

17. Nahar Sh., Hasegawa K., Kagaya Sh. Photocatalytic degradation of phenol by visible light-responsive iron-doped $\mathrm{TiO}_{2}$ and spontaneous sedimentation of the $\mathrm{TiO}_{2}$ particles // Chemosphere. - 2006. - V. 65, № 11. - P. 1976.

18. Chiou Ch.H., Juang R.Sh. Photocatalytic degradation of phenol in aqueous solutions by Pr-doped $\mathrm{TiO}_{2}$ nanoparticles // J. Hazard. Mater. - 2007. - V. 149, № 1. - P. 1-7.

19. Barakat M.A., Schaeffera H., Hayesa G., Ismat-Shah S. Photocatalytic degradation of 2-chlorophenol by Co-doped $\mathrm{TiO}_{2}$ nanoparticles // Appl. Catal. B: Environ. - 2005. V. 57, № 1. - P. 23-30.

20. Fu X.Z., Clark L.A., Yang Q., Anderson M.A. Enhanced Photocatalytic Performance of Titania-Based Binary Metal Oxides: $\mathrm{TiO}_{2} / \mathrm{SiO}_{2}$ and $\mathrm{TiO}_{2} / \mathrm{ZrO}_{2} / /$ Environ. Sci. Technol. 1996. - V. 30, № 2. - P. 647-653.

21. Li Z.J., Hou B., Xu Y. et al. Hydrothermal synthesis, characterization, and photocatalytic performance of silica-modified titanium dioxide nanoparticles // J. Colloids Interf. Sci. - 2005. - V. 288, № 1. - P. 149-154.

22. Yang L., Luo Sh., Li Y. et al. High efficient photocatalytic degradation of pnitrophenol on a unique $\mathrm{Cu}_{2} \mathrm{O} / \mathrm{TiO}_{2}$ p-n heterojunction network catalyst // Environ. Sci. Technol. - 2010. - V. 44, № 19. - P. 7641.

23. Li G., Dimitrijevic N.M., Chen L. et al. Role of Surface/Interfacial $\mathrm{Cu}^{2+}$ Sites in the Photocatalytic Activity of Coupled $\mathrm{CuO}-\mathrm{TiO}_{2}$ Nanocomposites // J. Phys. Chem. C. - 2008. V. 112, № 48. - P. 19040-19044.

24. Macwan D.P., Dave P.N., Chaturvedi Sh. A review on nano-TiO 2 sol-gel type syntheses and its applications // J. Mater. Sci. - 2011. - V. 46, № 11. - P. 3669-3686.

25. Исаев А.Б., Алиев 3.М., Адамадзиева Н.К. и др. Фотокаталитическое окисление азокрасителей на наночастицах $\mathrm{Fe}_{2} \mathrm{O}_{3}$ под давлением кислорода // Российские нанотехнологии. - 2009. - Т. 4, № 7-8. - С. 109-113. 
26. Исаев А.Б., Магомедова Г.А., Закаргаева Н.А., Адамадзиева Н.К. Влияние давления кислорода на фотокаталитическое окисление красителя хромового коричневого с использованием в качестве катализатора $\mathrm{TiO}_{2} / /$ Кинетика и катализ. -2011 . - Т. 52, № 2. - C. 204-208.

27. Bandara J., Udawatta C.P., Rajapakse C.S. Highly stable $\mathrm{CuO}$ incorporated $\mathrm{TiO}_{2}$ catalyst for photo-catalytic hydrogen production from $\mathrm{H}_{2} \mathrm{O} / /$ Photochem. Photobiol. Sci. 2005. - V. 4, № 11. - P. 857-861.

28. Lim T.H., Jeong S.M., Kim S.D. et al. Degradation Characteristics of NO by Photocatalysis with $\mathrm{TiO}_{2}$ and $\mathrm{CuO} / \mathrm{TiO}_{2} / /$ React. Kinet. Catal. Lett. - 2000. - V. 71, № 2. P. 223-229.

29. Aceituno M., Stalikas C.D., Lunar L. et al. $\mathrm{H}_{2} \mathrm{O}_{2} / \mathrm{TiO}_{2}$ photocatalytic oxidation of metol. Identification of intermediates and reaction pathways // Water Res. - 2002. - V. 36, № 14. - P. 3582-3592.

30. Chu W., Wong C.C. The photocatalytic degradation of dicamba in $\mathrm{TiO}_{2}$ suspensions with the help of hydrogen peroxide by different near UV irradiations // Water research. 2004. - T. 38, № 4. - C. 1037-1043.

31. Bertelli M., Selli E. Reaction paths and efficiency of photocatalysis on TiO 2 and of $\mathrm{H}_{2} \mathrm{O}_{2}$ photolysis in the degradation of 2-chlorophenol // Journal of hazardous materials. 2006. - T. 138, № 1. - C. 46-52.

32. Karunakan $C$., Senthilvelan $S$. $\mathrm{Fe}_{2} \mathrm{O}_{3}$-photocatalysis with sunlight and UV light: oxidation of aniline // Electrochemistry Communications. - 2006. - T. 8, № 1. - C. 95-101.

33. Brillas E., Sires I., Oturan M.A. Electro-Fenton process and related electrochemical technologies based on Fenton's reaction chemistry // Chemical Reviews. - 2009. - T. 109, № 12. - C. 6570-6631.

34. Herrmann J.M. Heterogeneous photocatalysis: state of the art and present applications in honor of Pr. R.L. Burwell Jr. (1912-2003), Former Head of Ipatieff Laboratories, Northwestern University, Evanston (III) // Top. Catal. - 2005. - V. 34, № 1-4. - P. 49-65.

Поступила в редакцию 31 сентября 2016 г.

UDC 544.478.12

DOI: $10.21779 / 2542-0321-2016-31-3-68-75$

\section{Kinetics of photocatalytic oxidation of phenol on $\mathrm{CuO}-\mathrm{TiO}_{2}$ at high oxygen pressure}

\section{F.F. Orudzhev, A.B. Isayev, F.G. Gasanova, N.S. Shabanov}

Dagestan State University; Russia, 367001, Makhachkala, M. Gadzhiyev st., 43 a; faridstkha@mail.ru,abdul-77@yandex.ru

The photocatalytic oxidation of phenol to composite semiconductor photocatalyst of titanium dioxide modified with copper oxide (II) under sunlight irradiation is studied. It is shown that the phenol oxidation process in the presence of oxygen increases the process efficiency about 1.2 times.

Keywords: phenol, composite photocatalyst, titanium dioxide, oxygen, quantum yield, kinetics.

Received 31 September, 2016

Вестник Дагестанского государственного

университета.

Серия 1. Естественные науки. 2016. Том. 31. Вып. 3 